\title{
Práticas sociais de escrita e variação linguística na aquisição do sistema alfabético
}

\author{
Marcia Lisbôa Costa de Oliveira \\ Universidade Estadual do Rio de Janeiro \\ Valéria Campos Muniz \\ Instituto Nacional de Educação de Surdos
}

\begin{abstract}
Resumo
Neste trabalho, discute-se a articulação entre alfabetização e letramento, a partir da análise de dados de aquisição da escrita alfabética e da construção da textualidade em seis textos produzidos por alunos do quarto ano do Ensino Fundamental de uma escola pública. A pesquisa é baseada nos Novos Estudos do Letramento, que são articulados às teorias variacionista e psicogenética para investigar o conhecimento de práticas sociais de escrita, bem como as interferências da oralidade na produção de textos, identificando índices da construção do conhecimento sobre o sistema da escrita. O objetivo é apresentar uma proposta metodológica que se situe na confluência das perspectivas teóricas abordadas, contemplando a complexidade do fenômeno da linguagem.

Palavras-chave: letramento, variação linguística, alfabetização.
\end{abstract}

\begin{abstract}
In this paper, we discuss the link between basic literacy ("alfabetização") and critical literacy ("letramento"), based on the analysis of the acquisition of writing and the construction of textuality in six texts produced by students in the fourth grade of an elementary public school. The research is based on the New Literacy Studies, which are, in turn, based on variationist and psychogenic theories for investigating the knowledge of social practices of writing, as well as the interference of orality in the production of texts. The study identifies indicators for the construction of knowledge about the writing system. The goal of the study is to present a methodology that conjoins the theoretical perspectives, considering the complexity of the phenomenon of language.
\end{abstract}

Keywords: literacy, linguistic variation, basic literacy.

\section{INTRODUÇÃO}

No paradigma contemporâneo, considera-se a alfabetização e o letramento como aspectos indissociáveis do processo de inserção na cultura letrada, embora cada um desses fenômenos guarde características próprias. Articulando esses dois conceitos, analisa-se a forma como alunos do quarto ano do ensino fundamental criam hipóteses sobre a lógica do 
sistema alfabético e como se constituem sujeitos na cultura letrada, incorporando conhecimentos acerca das práticas sociais da escrita.

Tomando por base os estudos sobre a aquisição inicial da lectoescrita, propõe-se uma reflexão sobre a transposição didática dessas concepções para a construção de uma proposta metodológica que contemple a complexidade do trabalho com a linguagem no ciclo da alfabetização.

O corpus analisado é composto por um conjunto de seis textos produzidos por alunos de uma escola pública, todos regularmente matriculados no quarto ano do Ensino Fundamental. Discutiremos os seguintes aspectos dos textos: (1) conhecimento de estruturas textuais e de práticas sociais de escrita; (2) variação linguística e escrita espontânea na alfabetização; (3) conhecimento do sistema da escrita e índices de elaboração de hipóteses acerca da escrita ortográfica.

\section{CONHECIMENTO DE ESTRUTURAS TEXTUAIS E DE PRÁTICAS SOCIAIS DE ESCRITA}

O conjunto de textos que compõe nosso corpus foi escrito em sala de aula: inicialmente foi feita pela professora a leitura de uma narrativa em que abelhas eram personagens que, a seguir, solicitou aos alunos que escrevessem uma história com os mesmos personagens. Constatou-se que a proposta gerou a produção de textos "intransitivos", uma vez que não considera a interação como constituinte da linguagem. Trata-se de uma "redação escolar", um gênero de texto que não tem lugar na vida social da linguagem.

Um aspecto que chama atenção nos textos é a falta de conhecimento de seus autores em relação às abelhas. Mesmo que se considerem os textos narrativos como mundos ficcionais, não se pode deixar de notar que esse desconhecimento implica um empobrecimento temático.

Isso pode ser claramente notado no conjunto dos textos, nos quais as crianças usam diferentes estratégias para preencher o espaço destinado à escrita (ver transcrições em anexo).

No texto I, a abelha é humanizada e sua casa apresentada como pouco segura pela ausência de uma porta, a qual foi instalada após o sumiço de objetos pessoais da abelha. Para construir sua narrativa, o aluno ativou conhecimentos sobre o mundo dos homens, sem nenhuma referência à especificidade da vida do animal. Procedimento semelhante é adotado pelo autor do texto VII, que humaniza a personagem, embora tome como referência para o mundo ficcional, por um processo de analogia, seus conhecimentos sobre pássaros. No texto 
II, a abelha vai à mata procurar mel para repartir com os porcos, sinalizando que o autor tem apenas uma vaga ideia da relação entre esse animal e o mel. Já o texto III usa uma estrutura narrativa bastante recorrente, especialmente em produções voltadas para o público infantil: um indivíduo que precisa vencer o medo para exercer plenamente sua identidade. Esse é o caso da abelha que tinha medo de voar, mas, com a ajuda da amiga, superou o medo, "aprendeu a lisão[sic] e viveu feliz para sempre". Reproduzindo esse padrão narrativo, a autora também evita o enfrentamento das especificidades da vida da personagem-animal.

Os exemplos IV e V constituem textos típicos do universo escolar, pois, entre outros traços, apresentam pouco conteúdo e utilizam expressões padronizadas, tais como: "ela era amiga de todo mundo", "ela era bonitinha" e "ela era muito lega[1]". No texto IV, nota-se o recurso à sonoridade e à repetição, que podem ser vistas tanto como recursos de estilo, quanto como uma estratégia para o preenchimento das linhas apresentadas na "folha de redação". Os dois textos são muito semelhantes quanto ao enredo, às estruturas frasais e ao vocabulário empregado, o que pode indicar a presença de um processo de autoria "compartilhada". Destaque-se, nesse aspecto, a presença em ambos do verbo "zubizar", sem registro dicionarizado, que parece ser uma variante não padrão do verbo zumbir.

O baixo nível de informatividade dos textos acima está relacionado à distância entre o repertório necessário à construção de uma "história sobre abelhas" e o efetivo conhecimento dos alunos sobre esse animal. Esse desencontro entre as expectativas da professora e os conhecimentos dos alunos fica patente na relação entre a proposta e seu produto, que configura um gênero eminentemente escolar.

Examinar-se-ão a seguir aspectos da oralidade que repercutem nas hipóteses construídas pelos aprendizes.

\section{VARIAÇÃO LINGUÍSTICA E ESCRITA ESPONTÂNEA NA ALFABETIZAÇÃO}

As duas questões que se colocam para o aprendiz diante do desafio de compreender o sistema de escrita alfabética (SEA) são: desvendar o que representam as letras e entender como funciona esse sistema de representação (FERREIRO, apud MORAIS, 2012). Assim, elas tentam compreender os conceitos e as convenções implicadas na organização do SEA, processo de evolução que vai passa pelas fases pré-silábica, silábica, silábico-alfabética, até 
chegar à escrita alfabética. A ortografia é, portanto, uma aquisição progressiva e posterior, configurando num percurso mais longo de contato com as convenções da escrita.

Pesquisas desenvolvidas a partir do paradigma psicogenético, ultrapassando a modelização e a fixidez estruturalista, que caracterizam essa abordagem, demonstram que o processo de construção dos aprendizes apresenta peculiaridades e particularidades que não se restringem às grandes fases descritas por Ferreiro, e, embora não as neguem, indicam a necessidade de flexibilização de seus princípios (SMOLKA, 2012; GOULART, 2005; GOULART e WILSON, 2013; TOLCHINSKY, 2006).

De toda forma, o que o aprendiz toma como referência é a oralidade, que funciona como ponto de partida para a elaboração de hipóteses acerca das relações entre letras e sons. A partir do contato e da reflexão sobre as formas escritas com que convive, ele vai usá-las também como base para suas elaborações e reelaborações hipotéticas.

A modalidade oral tende a apresentar marcas de variação social mais evidentes do que as que ocorrem na forma escrita, o que constitui um fator de complexificação no momento da aprendizagem do SEA. Na escola pública, que recebe muitos alunos falantes das variedades de menor prestígio social, faz-se necessário desenvolver estratégias para, de um lado, garantir espaço para a expressão desses sujeitos em suas modalidades linguísticas maternas (orais) e, de outro, possibilitar-lhes o domínio das formas da língua valorizadas socialmente (orais e escritas).

O ensino da escrita, nesse contexto, deve considerar o fato de que o domínio do sistema ortográfico é particularmente complexo para os falantes das variedades do português nãopadrão, uma vez que seus conhecimentos fonológicos tendem a gerar formas escritas que divergem da escrita convencional. Isso deve ser uma preocupação constante do professor ao longo do ensino fundamental.

Sabe-se que, no processo de aquisição inicial da lectoescrita, a escrita fonológica é uma etapa importante, que deve, no entanto, ser superada. Isso foi esclarecido pelos estudos sobre a psicogênese da língua escrita, acima mencionados, que revelaram a importância do entendimento da relação entre grafemas e fonemas como base para a compreensão do sistema alfabético e o domínio efetivo da escrita.

Estudos recentes também indicam que a consciência fonológica está diretamente relacionada à aprendizagem da leitura, não necessariamente como um pré-requisito, mas como uma capacidade metalinguística que permite ao aprendiz refletir sobre as relações entre 
grafemas e fonemas, a fim de gradativamente internalizar regularidades ortográficas e também irregularidades, sobretudo aquelas presentes em vocábulos de uso mais constante. Para isso, é fundamental que a criança perceba que nem todas as palavras seguem regras definidas, sendo necessário um trabalho que conjugue oralidade e escrita e permita reflexão sobre semelhanças e diferenças entre as formas de representar as palavras.

Cagliari (1999) destaca dois tipos de escrita que ocorrem na passagem da hipótese de que a escrita transcreve a fala até a percepção da convenção ortográfica: fonográfico-fonética e alfabético-ortográfica. Quando a criança já se encontra no segundo tipo, os conflitos são menores, pois, tendo consciência do convencionalismo das regras, não se atém tanto à pronúncia e busca a forma correta da grafia da palavra. Ou seja, a passagem da escrita fonográfico-fonética para a escrita alfabético-ortográfica indica o início da conscientização de que a escrita representa a língua e não a fala.

Dessa forma, para se tornar ortográfica a criança precisará abandonar a hipótese de que a língua escrita representa especularmente a fala e compreender que a ortografia padroniza e neutraliza a diversidade dos modos de falar português. Isso não significa, no entanto, uniformidade na leitura.

Seymour (2008) demonstrou que o aprendizado da ortografia é mais lento ou mais rápido, dependendo da complexidade das estruturas silábicas e da profundidade da ortografia de cada sistema linguístico. Para ele, os sistemas ortográficos 'profundos' (deep) apresentam relações complexas entre grafemas e fonemas, bem como estruturas silábicas compostas por séries de encontros consonantais. Já os sistemas ortográficos 'rasos'(shallow) tendem a apresentar sílabas simples, com estruturas canônicas do tipo consoante + vogal. A escala comparativa de complexidade ortográfica construída por Seymour a partir dos "erros" apresentados pelos aprendizes revela que a língua finlandesa está no nível de menor complexidade, pois apresenta ortografia 'rasa' e estruturas silábicas simples, enquanto o inglês está no nível de maior complexidade, com ortografia 'profunda' e estruturas silábicas complexas. O sistema do português europeu apresenta alto grau de profundidade ortográfica, sendo superado nesse quesito apenas pelo francês, pois apresenta estruturas silábicas simples.

Embora essa pesquisa tome por base a variante portuguesa, acredita-se que suas conclusões sobre o desempenho dos aprendizes podem ser úteis para os professores brasileiros. Entre as línguas com estrutura silábica simples - finlandês, grego, italiano, espanhol, português e francês -, os iniciantes apresentaram mais "erros" na decodificação de 
'não-palavras' simples (sequências de sílabas simples, sem significação nessas línguas). Em ambos os casos, a ortografia é 'profunda'. A fluência na leitura também é afetada por essas dimensões, o que aumenta o tempo necessário para o aprendiz tornar-se fluente. Segundo Seymour, os leitores iniciantes nas línguas portuguesa, francesa e dinamarquesa leem corretamente $75 \%$ das palavras familiares a eles apresentadas antes do fim do primeiro ano escolar, em contraste com o índice de 95\% observado entre iniciantes na lectoescritura das demais línguas estudadas. Já os leitores iniciantes em inglês leem de maneira correta somente $34 \%$ dos vocábulos nessa mesma fase, o que pode ser tomado como indicador do impacto da profundidade desse sistema ortográfico no processo de aquisição da lectoescrita (SEYMOUR, 2008).

Ainda não está claro como a profundidade ortográfica relaciona-se com leitura e a soletração correta na escrita. No entanto, pode-se afirmar que em sistemas vocálicos simples, como o português, as crianças tendem a errar mais no uso de consoantes do que no das vogais. No português brasileiro, a correspondência entre o nome das vogais e seu som é um fator de facilitação (BABAYIGIT, 2009). Mesmo assim, são frequentes as trocas entre vogais em virtude de enganos provenientes da pronúncia, gerando escritas como "mininu” na fase inicial de aquisição do código escrito.

Quando a criança ainda não detém um acervo de imagens de palavras a que possa recorrer, é inevitável uma aproximação com a pronúncia, acarretando construções como: "muito", “boua”, “beim”. Esse tipo de hipótese apresenta um grau de dificuldade inferior àqueles gerados por situações em que mais de uma letra representa o mesmo som, como, por exemplo, o s (não intervocálico), ss, ç, c, sc, para a fricativa alveolar desvozeada /s/; s, z, para a fricativa alveolar vozeada/z/ etc, cuja saída, muitas vezes, é a memória visual. A habilidade em detectar qual a letra a ser utilizada é um dos sucessos da escrita ortográfica. Essa falta de coincidência entre letra e som, uma vez que não há relação única, conforme descrito, torna-se um desafio para a criança em fase de alfabetização. Diversos estudos ressaltam consequências positivas na escrita e leitura quando a criança adquire consciência fonológica:

Enquanto a consciência de alguns segmentos sonoros (supra-fonêmicos) parece desenvolver-se espontaneamente, a consciência fonêmica parece exigir experiências específicas em atividades que possibilitem a identificação da correspondência entre os elementos fonêmicos da fala e os elementos grafêmicos da escrita (ALÉGRIA, LEYBAERT \& MOUSTY, 1994/1997; BERTELSON, MORAIS, ALEGRIA \& CONTENT, 1985; DEMONT, 1994/ 1997; PERFETTI, BECK, BELL \& HUGHES, 1987 , citado em GUIMARÃES, 2002, p. 248). 
Esse conhecimento é construído à medida que a criança escreve, pois, produzindo textos espontâneos, ela tem oportunidade de pensar sobre o sistema e reelaborar suas hipóteses.

\section{CONHECIMENTO DO SISTEMA DA ESCRITA E HIPÓTESES ORTOGRÁFICAS}

Examinando o conhecimento do sistema da escrita e índices de elaboração de hipóteses sobre a escrita alfabética em dois dos textos que compõem o corpus, pode-se perceber os índices da atividade produtiva de um sujeito cognoscente que aprende a escrever enquanto escreve.

No texto I, embora o aluno esteja em seu quarto ano de escolarização, percebe-se que ele se encontra no nível de alfabetização que Emília Ferreiro (1993) definiu como alfabético, pois sua escrita funciona como transcrição fonética da fala. Dessa forma, muitas hipóteses divergentes de grafia são frutos de transcrição fonética, uso inadequado de letras, hipercorreção, juntura e segmentação, estando diretamente relacionados à variante do falante.

O fato de utilizar o dígrafo "nh" para grafar a palavra abelha demonstra que ele já esteve em contato com essa convenção ortográfica, mas não consegue associá-la à sonoridade que pretende registrar. Do mesmo modo, o fonema /s/ intervocálico é constantemente representado pelo grafema z, como em "cuidadosa" e "cozas"; opondo-se ao fonema / $/$ / em posição final nos vocábulos, grafado s, como em "fes" e "féis". Ou seja, verifica-se que há uma sistemática no emprego de alguns grafemas associados a determinados fonemas, até a assimilação da escrita correta.

No caso do grupo de força /erapase/, que transcreve o sintagma "era para ser", há um vocábulo fonológico criado pela superposição do verbo aos componentes da oração adverbial final reduzida de infinitivo. Essa junção confirma a não coincidência entre vocábulo fonológico e vocábulo formal, observando-se também um traço da oralidade na redução da preposição para.

É justamente a concepção da relação entre oralidade e escrita que gera tais oscilações no tocante à segmentação dos vocábulos, indicando que o aprendiz está em processo de construção de hipóteses no que diz respeito à separação das palavras e, para isso, orienta-se por conhecimentos linguísticos fundados na oralidade: um "saber fonológico", um "saber morfológico" e um "saber semântico". Segundo Castello (1990), uma vez compreendida a 
necessidade de separar os vocábulos na escrita, os aprendizes passam a acionar diferentes conhecimentos gramaticais, buscando hipóteses que lhes permitam segmentar corretamente os enunciados que produzem. O "saber fonológico" os leva a separar as palavras escritas de acordo com os "grupos de força da língua oral", especialmente as formas dependentes (artigos, preposições, pronomes átonos e partículas conectivas), como apresentado nos seguintes registros:

a) Junção do artigo ao substantivo: "ascoz-as" (as coisas) ; "umacoza" (uma coisa); "aporta" ( a porta)

b) Junção do verbo ao artigo: "feja” (fez a)

Quando o "saber morfológico" é ativado, a coincidência gráfico-fonológica entre fonemas iniciais das palavras e fonemas das formas presas leva à hipersegmentação do vocábulo (CASTELLO, 1990). Isso é o que ocorre na grafia de "a benha", em que a letra a inicial é interpretada como um artigo. Um dado interessante é a segunda ocorrência desse vocábulo, o qual no título é grafado como uma só palavra. Outras oscilações desse tipo aparecem no texto, mas sua motivação parece ser diversa.

No caso das grafias divergentes "elafes/ela féis", além de hipóteses distintas quanto à segmentação vocabular e às transcrições fonológicas diferentes para o mesmo sintagma, constata-se, na segunda forma, o acréscimo de um acento e a epêntese da semivogal i, uma característica da variante falada em algumas cidades do Brasil.

A junção do sujeito expresso pelo pronome pessoal ao verbo caracteriza a influência de um "saber semântico", "constituindo vocábulos formais segundo unidades conceituais" (CASTELLO, 1990). O usuário da língua une os vocábulos, como nas seguintes ocorrências: "erapase"; "elaco";" bonitaeeelaeramuta".

A segmentação inadequada também se evidencia no segundo texto, nas ocorrências "namatu" e "umonte". Há ainda grafemas diferentes representando sons silábicos vocalizados: "procurol" (procurou), "axol” (achou) e "meu” (mel). Um traço da oralidade é a grafia dos verbos grafados sem o /r/ de infinitivo: "cume" e "voa". No tocante à flexão verbal, há a confusão de grafia entre o pretérito perfeito e o futuro do presente: "comesarão" (começaram) e "dividirão" (dividiram).

Outro uso frequente verificado no texto II é o acento no conectivo "e" grafado como "é": "A belia é os porcos", "A belia foi namatu é axol". Entretanto, há momentos em que a 
criança emprega o conectivo sem acento: "E foi no canto é comesarão a cume o mel e depois".

Assim como no texto I, a palavra abelha é grafada separadamente, "a belia". Verifica-se ainda nessa palavra uma ocorrência proveniente de pronúncia, a grafia do dígrafo "lh" como a sílaba "li", isto é, ocorre a despalatalização. Processo semelhante ocorre no texto VI em "abelinha e filinha".

\section{LETRAMENTO E AQUISIÇÃO DO SISTEMA DA ESCRITA: PROPOSIÇÕES TEÓRICO-METODOLÓGICAS}

De acordo com Teberosky (1990), a leitura e a escrita não são "ensinadas", cabe ao professor criar e planejar situações que possibilitem às crianças o alcance desse objetivo. Passa-se de transmissor a mediador do processo, pois, se a criança já teve contato com a escrita em circunstâncias sociais diversas ao longo da sua vida, o professor deve, a partir dessa constatação, investigar o saber prévio da criança e propor situações funcionais à produção de texto. Ao reconhecer uma função para a escrita, a aprendizagem se constrói, solidificando um saber que vai além da simples memorização de letras. O professor mediador cria circunstâncias familiares ao aluno, propiciando afinidade e motivando a escrita. Com o tempo, o contato com gêneros textuais variados favorecerá a compreensão do sistema alfabético.

Dessa forma, as atividades propostas devem ser significativas para a criança, de modo que ela sinta necessidade de expor ideias e opiniões. Cabe ao professor criar situaçõesproblema, envolvendo a linguagem, a fim de que ela compreenda a função social da escrita e reconheça progressivamente a necessidade de adequar o conteúdo e a forma de seu discurso aos diferentes gêneros.

Prejudica-se esse processo quando se desconsidera que a língua é instrumento de interlocução e se propõe a construção de textos artificiais, cujo único interlocutor é o professor. Esse tipo de abordagem insere-se no campo do chamado Letramento autônomo (STREET, 2014), pois neutraliza os aspectos socioculturais da produção de textos e, de acordo com Mortatti, transforma os gêneros em "objetos de ensino, incorporados ao currículo, aos programas, aos projetos pedagógicos" (2004, p. 114). Assim, segundo a mesma autora: 
/.../ o letramento passa a integrar uma cultura especificamente escolar, entendida como certos eventos e práticas (de letramento) que, selecionados,organizados, normatizados sob o efeito dos imperativos de didatização, passam a constituir o objeto de uma transmissão deliberada no contexto das escolas. (2004, p. 114).

Articulando alfabetização e letramento, é necessário planejar estratégias de ensino que garantam uma transposição didática adequada, levando em consideração a presença de diferentes saberes em circulação nesse processo. Isso é bastante importante, pois, como alerta Chevalard (apud BRONCKART, 2010), muitas vezes, em lugar do saber acadêmico, outros saberes basearam as formulações pedagógicas no ensino de línguas.

Tal equívoco ocorreu tanto no ensino da produção de texto, quanto no da ortografia, em que uma secular tradição foi incorporada acriticamente ao cotidiano das salas de aulas. Em torno desses conteúdos, constituiu-se uma noosfera, conceito oriundo da Filosofia e ressignificado por Chevallard, como discurso que se constrói à margem das teorias pedagógicas e atua sobre a organização didática dos saberes a ensinar (BRONCKART, 2010), o qual naturalizou determinadas estratégias que se sedimentaram ao longo dos tempos, como: ditados, cópias, exercícios de preenchimento de lacunas e redações. Subjaz a esse tratamento didático a concepção de língua como código a ser memorizado, o que explica a ênfase na repetição como estratégia mnemônica.

Nas últimas décadas, refletindo mudanças na noosfera educacional brasileira, observase a presença crescente de propostas que adotam a perspectiva apresentada nos Parâmetros Curriculares Nacionais e em outros discursos que atuam sobre a didatização do processo de aquisição inicial da lectoescrita. Apesar dos inegáveis avanços carreados por essas mudanças, no entanto, ainda há muito a pesquisar e a sistematizar para que se concretize a transposição didática das teorias de referência para o ensino e da aprendizagem da língua.

$\mathrm{Na}$ noosfera, que atua sobre o sistema de ensino brasileiro contemporâneo, estão em evidência diferentes saberes acadêmicos. Portanto, para uma definição metodológica coerente com o saber acadêmico na área, é preciso articular um mosaico que inclui, entre outros conhecimentos, teorias sobre a aquisição da lectoescrita, descrições do sistema alfabéticoortográfico, estudos variacionistas e pesquisas sobre o letramento.

Teberosky (1990) ressalta que o diagnóstico dos conhecimentos dos alunos é a base para o planejamento do professor e afirma que a análise das produções indicia "as ideias e conhecimentos das crianças e quais expectativas podemos ter para proporcionar, depois, situações de ensino aprendizagem”. Portanto, o conteúdo programático anual deve estar em 
consonância com as necessidades dos alunos, uma vez que, havendo complementaridade de informações, há aprendizado.

Como alternativa para se trabalhar a textualidade e os conhecimentos sobre o sistema da escrita, partilha-se da opinião de Ferreiro (2001), que propõe levar a criança a corrigir o próprio texto, alternando papéis - escritor e leitor -, a fim de perceber que seu texto, ao ser lido por outras pessoas, precisa ser compreendido. Essa autocorreção permite reflexão sobre a escrita, além de contribuir para construção de memória visual, que contribuirá para diminuição de futuras escritas divergentes do padrão ortográfico. A criança, ciente de que a escrita torna concretos fatos abstratos e da não correspondência entre fonema e letra, inicia outro período no seu aprendizado, o da escrita alfabética, momento de observação e compreensão dos processos de construção da estrutura da língua.

Para ajudá-la a se conscientizar de que a palavra constitui uma unidade fonológica que se distingue do grupo de força, um dos caminhos pode ser a leitura pausada da frase em voz alta, com sinalização gestual da pauta sonora dos enunciados, a fim de que perceba a individualidade de cada um dos vocábulos. Tentativas de representação como essa são um importante estágio da aprendizagem. "Não há um processo cumulativo simples, unidade por unidade, mas organização, desestruturação e reestruturação contínua” (FERREIRO, 1993, p. 31).

Note-se também que os estudos ligados à perspectiva variacionista iluminam aspectos da relação entre oralidade e escrita por muito tempo ignorados pela escola, que é tradicionalmente grafocêntrica. A compreensão das relações entre língua e sociedade é fundamental para o combate ao preconceito linguístico que ainda está muito presente no discurso escolar, bastante refratário à noção da pluralidade linguística. Este permanece atrelado à concepção monolítica da língua, e, em consequência, à ideia de erro.

Considerando-se a regionalidade, percebe-se que os diferentes modos de falar a língua portuguesa que formam o caleidoscópio brasileiro levarão, inevitavelmente, a diferentes dificuldades na compreensão da relação entre grafemas e fonemas para os falantes. Sabe-se que a relação entre oral e escrito é bastante complexa e não pode ser colocada em termos de oposição. Por isso mesmo, para ensinar com eficácia o sistema alfabético-ortográfico, o docente deve ter os conhecimentos linguísticos que o habilitem a diagnosticar as dificuldades apresentadas pelo grupo com o qual trabalha. Somente então poderá planejar estratégias metalinguísticas e epilinguísticas adequadas. 
Considerando o corpus analisado neste trabalho, por exemplo, percebe-se que há grande necessidade de sistematizar o conhecimento sobre dígrafos. Nesse caso, a elaboração de sequências didáticas contextualizadas poderia ser bastante eficaz. O mesmo não se aplica, no entanto, às inúmeras ocorrências de hipossegmentação e de hipersegmentação constatadas nos textos I e II, situações em que a leitura em voz alta com marcação de pauta sonora e o trabalho com letras de música, para confronto e comparação entre os grupos de força que se formam na fala e as "fronteiras" entre os vocábulos seriam estratégias interessantes.

Caso diferente pode ser destacado na ocorrência "precurou", que transcreve a forma como o verbo procurar é articulado por falantes das formas populares da língua na região em que está localizada a escola. Nesse caso, o tratamento da variação linguística, sempre de forma respeitosa, precisa sublinhar as diferenças em o modo de falar e o modo padronizado da escrita.

No tocante aos saberes a ensinar, tanto os PCNs quanto as matrizes de avaliação trabalham com a noção de competências e capacidades linguísticas, em lugar da listagem de conteúdos que se fazia tradicionalmente. Nesse contexto, a Matriz de Avaliação Diagnóstica da Alfabetização apresentada na apostila do Programa Pró-Letramento (BATISTA et al., 2007) define as expectativas de aprendizagem ao longo dos três primeiros anos do ensino fundamental e divide as capacidades linguísticas em cinco eixos: compreensão e valorização da cultura escrita; apropriação do sistema de escrita; leitura; produção escrita e desenvolvimento da oralidade.

O segundo eixo envolve os conhecimentos, capacidades e atitudes relacionadas à compreensão do funcionamento da escrita. No quadro que figura na página 24 do documento, relacionado à apropriação do sistema da escrita, os conhecimentos e capacidades são listados em grau crescente de dificuldade e as capacidades relacionadas ao domínio ortográfico são elencadas ao final da tabela: relações entre grafemas e fonemas; regularidades ortográficas e irregularidades ortográficas. A expectativa de aprendizagem dessas capacidades não está colocada, no entanto, como um aprendizado a ser completamente alcançado nos três anos iniciais do ensino fundamental, elas devem ser introduzidas no primeiro ano, introduzidas e trabalhadas no segundo ano, trabalhadas e consolidadas no terceiro ano. Portanto, infere-se que os anos seguintes serão destinados à retomada sistematizadora das relações entre grafemas e fonemas. (BATISTA et al., 2007) 
No corpus analisado, encontram-se problemas no alinhamento da escrita e várias ocorrências de hipersegmentação e de hipossegmentação, notadamente nos dois primeiros textos. Nesse caso, trata-se de situações que não seriam mais esperadas no quarto ano de escolarização, uma vez que o domínio da convenção gráfica é uma capacidade que deve ser enfatizada no primeiro ano, durante o qual deve ser introduzida, sistematizada e consolidada. No segundo e no terceiro anos, espera-se que haja somente a retomada dessa capacidade. No quadro de habilidades e conhecimentos que analisamos, evidencia-se que a expectativa de aprendizagem pertence ao primeiro ano, enquanto os dois seguintes deveriam apenas contribuir para a consolidação desse conteúdo (BATISTA et al., 2007). Ou seja, a base ortográfica deveria desenvolver-se ao longo dos três anos iniciais do ensino fundamental.

Constata-se, no entanto, que a ortografia é ensinada de forma genérica nos anos iniciais e negligenciada como conteúdo nos anos finais do ensino fundamental. Além disso, uma metodologia desatenta às variantes linguísticas e às necessidades específicas dos indivíduos tem permitido que até mesmo alunos de ensino médio apresentem grafias divergentes do padrão ortográfico na representação de regularidades contextuais e de regularidades morfológicas elementares.

\section{CONSIDERAÇÕES FINAIS}

Na perspectiva dos novos estudos sobre o letramento, não há apenas uma forma de usar a língua escrita - a reconhecida e legitimada pelas instituições que detêm o poder, à qual poucos têm acesso -, mas há “ múltiplas formas de usá-la, em práticas diversas que são sociocultural e historicamente determinadas" (KLEIMAN, 2008, p. 490).

Nesse sentido, é importante criar situações didáticas nas quais a leitura e a escrita sejam compreendidas como um processo discursivo, recriando situações sociocomunicativas em que os textos produzidos estejam carregados de sentido e função, de modo a favorecer "uma interação entre exigências sociais e competências individuais" (MORTATTI, 2004, p.84).

Os resultados dessa pesquisa, ainda em andamento, sugerem que o processo de aquisição da escrita mescla-se ao conhecimento sobre seus usos e funções na sociedade. Assim, as atividades de compreensão e a produção de textos, desde o início da aquisição da lectoescrita, podem propiciar diversos níveis de elaboração, que vão da escolha lexical à 
compreensão de nexos sintáticos e à conexão entre as diversas partes do texto, incorporando também a reflexão sobre os significados socioculturais do letramento.

Conforme constatado na análise do corpus, na fase inicial do aprendizado, as crianças demonstram nas suas redações aspectos da oralidade advindos da forma dialetal de sua comunidade, além de hipóteses provenientes do intercruzamento fonético e fonológico da escrita. Apenas gradativamente, elas passam a ter o entendimento de que a representação ortográfica não é baseada na forma fonética, e de que não há uma relação biunívoca entre letra e som. Diferentemente das representações escritas de base fonética, as fonológicas, oriundas da troca entre grafemas semelhantes, comprovam a não vinculação com a oralidade e evidenciam uma dificuldade inerente ao sistema ortográfico. Compreender esses estágios é fundamental para o docente propor exercícios compatíveis, para construir negociações entre a complexidade do sistema alfabético e os conhecimentos e habilidades já desenvolvidos pelos aprendizes.

Como atividade de ensino, na linha de pensamento de Ferreiro (2001) e Teberosky (1990), propõem-se exercícios que levem à reflexão, despertando cognitivamente as crianças para aspectos fonológicos, fonéticos e ortográficos presentes na escrita. No que diz respeito ao aspecto arbitrário e convencional da escrita, é interessante o trabalho com textos significativos, a fim de desenvolver capacidade metalinguística de reflexão entre grafemas e fonemas, de forma que se internalizem as regularidades ortográficas e se possa perceber a existência de situações em que o sistema apresenta irregularidades.

Tendo em vista que a variante linguística falada pelo aprendiz impacta suas hipóteses acerca da representação escrita dos vocábulos, considera-se fundamental que esse fator seja tomado em consideração ao longo do processo de ensino-aprendizagem do sistema alfabético e das normas ortográficas.

\section{REFERÊNCIAS}

BATISTA, A. A. G. et al. Capacidades Linguísticas: Alfabetização e Letramento. In: Corrêa, S. \& Godoy, S. Pró-Letramento: Alfabetização e Linguagem. Brasília: MEC/SAEB, p. 857, 2007.

BABAYIGIT, S. Reading and spelling development in transparent alphabetic orthographies: Points of convergence and divergence, 2009. Disponível: http://eprints.uwe.ac.uk/11699/. 
BRONCKART, J. P. Desarrollo del lenguage y didática de las lenguas. Buenos Ayres: Miño y Dávila, 2010.

CAGLIARI, L.C. A ortografia na escola e na vida. In: CAGLIARI, L.C., MASSINICAGLIARI, G. Diante das letras: a escrita na alfabetização. Campinas, SP: Mercado das Letras, p. 61-96, 1999.

CASTELLO, M. C. C. A constituição do vocábulo formal no texto escrito. In: AMORIM, M. (org.) Psicologia escolar: artigos e estudos. Rio de Janeiro: UFRJ, p. 27-37,1990.

FERREIRO, E. Cultura Escrita e educação: Conversas de Emília Ferreiro com José Castorina, Daniel Goldin e Rosa María Torres. Porto Alegre: Artmed, 2001.

Com todas as letras. São Paulo: Cortez, 1993.

GOULART, C. A produção de textos escritos narrativos, descritivos e argumentativos na alfabetização: evidências do sujeito na linguagem. In: ROCHA, G., COSTA Val, M.G. (Orgs.). Reflexões sobre práticas escolares de produção de texto: o sujeito autor. Belo Horizonte: CEALE/Autêntica, p. 85 a 107, 2005.

GOULART, C e WILSON, V. (Orgs.). Aprender a escrita, aprender com a escrita. São Paulo: Summus, 2013.

GUIMARÃES, S. R. K. Dificuldades no desenvolvimento da lectoescrita: o papel das habilidades metalinguísticas. Psicologia: Teoria e Pesquisa, 18 (3), p. 247-259, 2002.

KLEIMAN, A. B. (Org.) Os significados do letramento: uma nova perspectiva sobre a prática social da escrita. Campinas: Mercado das Letras, 2008.

MORAIS, A. G. de. Sistema de Escrita Alfabética. São Paulo: Melhoramentos, 2012.

MORTATTI, M.R.L. Educação e Letramento. São Paulo: UNESP, 2004.

SEYMOUR, P. H. K. Early Reading Development in European Orthographies, 2008. Disponível em http://www.pitt.edu/ perfetti/PDF/Seymour.pdf.

SMOLKA, A.L.B. A criança na fase inicial da escrita: a alfabetização como processo discursivo. São Paulo: Cortez, 2012.

STREET, B. Letramentos sociais. São Paulo, Parábola, 2014.

TEBEROSKY, A. Psicopedagogia da linguagem escrita. São Paulo: Editora da UNICAMP/Trajetória Cultural, 1990.

TOLCHINSKY, L. Escritura Y conocimiento Linguístico. Memorias del Encuentro Internacional de Linguística del Noroeste. Hermosillo, Sonora: Unison, 2006. Disponível em: http://www.ub.es/recerca/grerli/publicacions/Ponencia_México.pdf. 


\title{
AS AUTORAS
}

Marcia Lisbôa Costa de Oliveira é doutora em Letras (UFRJ, 2002). É professora da Universidade do Estado do Rio de Janeiro, atuando na Faculdade de Formação de Professores, no Departamento de Letras. Membro do corpo docente do Mestrado Profissionalizante em Letras - PROFLETRAS e da Especialização em Estudos Literários na FFP/UERJ. Tem experiência em projetos de Letramento Literário e desenvolve pesquisas sobre letramento e desigualdade social. Atua principalmente nos seguintes temas: leitura e formação de leitores, letramento de jovens e adultos, metodologia do ensino de língua portuguesa e formação de professores. Membro do Grupo de Pesquisa "Linguagem \& Sociedade" (FFP/UERJ-CNPq).

E-mail: lisboamarcia@hotmail.com

Valéria Campos Muniz é doutora em Língua Portuguesa (2013) e mestre Língua Portuguesa, (1997) pela Universidade do Estado do Rio de Janeiro. Professora adjunta de Língua Portuguesa como L2 - 40 horas com dedicação exclusiva - do INES. Tem experiência na área de Letras e atua principalmente nas seguintes áreas: leitura, aquisição da língua escrita, língua portuguesa como L2, gramática e ensino. Possui publicação em anais de eventos nacionais, internacionais, e em revistas. Área de interesse: linguística textual, estudos do letramento e língua portuguesa como L2. Membro (pesquisador) do Grupo de Pesquisa Linguagem \& Sociedade (FFP/UERJ-CNPq).

\author{
ANEXO 1 \\ Texto I \\ abenha \\ A benha é muta bonitaeeelaeramuta \\ cuidadoza com as cozas dela somiu ascoz \\ as dela $\mathrm{O}$ que elafes ela feis umacoza qui \\ erapase feta feja aporta elaco
}

\section{Texto II}

abenha

A benha é muta bonitaeeelaeramuta

cuidadoza com as cozas dela somiu ascoz

as dela $\mathrm{O}$ que elafes ela feis umacoza qui

erapase feta feja aporta elaco

\section{Texto III}

A abelinha Sara 
Era uma vez uma abelinha que [nome] se chamava Sara ela tinha medo de voa ela não comsequia um dia ela encontrou uma amiginha o nome dela era rafaela esa amigunha deu um comselho que era para ela não ter medo e sequir em frente ela respirou fundo e vuou e quando ela viu já estava voando e ela aprendeu a lisão e viveu feliz para sempre

Fim

\section{Texto IV}
A abelha
Era uma vez uma abelha
que adora zubiza
Ela não morde e nem
pica ela e amiga de
todo mundo você pode
até pegar o mel dela
que ela só sabe zubiza
zubiza, zubiza e enm
para comer zubiza
zubiza e so sabe
corre FIM

\section{Texto V}

A abelinha

Era uma vez

a abelinha Era muita

bonitinha Ela fazia zubiza

Ela Era Muita

bonitinha Ela não picava não mordia

Era Muita lega

Eu brincava muita

Com Ela quando

Eu soutava Ela

Era muito divertido

Aí vem $\mathrm{O}$ FIM 


\section{Texto VI}

A abelinha e seus filhotes

Era uma vez uma Abelinha que vuava e vuava num di a abelinha foi sai e deixou seus ovinho lá no ninho e quando ela voutou seu ovinho sumiru e ela precurou e precurou ela falou pa a amiga você viu meu ovinhos não margarida iagora cauma filha seus filhote ja naiseram e elis estam brincando $(\mathrm{m})$ com os coleguinhos brincando e suas filinhas estam brincando com suas coleginhas brincando parabens filha agora eu vou ser avo ...Fim 